\title{
The Outcome of Transvesical Prostatectomy-A Multicenter Retrospective Study
}

\author{
Bashir Yunusa' ${ }^{1}$, Ayun Cassell2 ${ }^{2}$, Solomane Konneh ${ }^{1}$, Swaliho Sheriff ${ }^{1}$, Edet Ikpi ${ }^{1}$ \\ ${ }^{1}$ Department of Surgery, Liberia College of Physicians and Surgeons, Monrovia, Liberia \\ ${ }^{2}$ Département d’Urologie et d'Andrologie, Hôpital Général de Grand Yoff, Dakar, Sénégal \\ Email: ay uncasselliii@gmail.com
}

How to cite this paper: Yunusa, B., Cassell, A., Konneh, S., Sheriff, S. and Ikpi, E. (2019) The Outcome of Transvesical Prostatectomy-A Multicenter Retrospective Study. Open Journal of Urology, 9, 85-92. https://doi.org/10.4236/oju.2019.95010

Received: April 25, 2019

Accepted: May 28, 2019

Published: May 31, 2019

Copyright (c) 2019 by author(s) and Scientific Research Publishing Inc. This work is licensed under the Creative Commons Attribution International License (CC BY 4.0).

http://creativecommons.org/licenses/by/4.0/

(c) (i) Open Access

\begin{abstract}
Background: Benign Prostatic Hyperplasia (BPH) is one of the commonest causes of lower obstructive uropathy and usually presents with lower urinary tract symptoms. However, in developing nations, the presentation is late often large prostate and associated complications of bladder outlet obstruction (diverticulae, stones, impaired renal function etc.) warranting open prostatectomy. Objective: The objective of this study is to share our experience of perioperative outcomes of open transvesical prostatectomy over a year involving two referral centers in Monrovia Liberia. Methodology: This was a retrospective study performed at The John F. Kennedy Medical Center and the Saint Joseph Catholic Hospital involving a total of 31 patients. Results: The mean age was 64.6 years $(\mathrm{SD}=9.03)$ with a range $52-85$ years. The study showed that $54.8 \%(17 / 31)$ of patients had preoperative catheter. The maximum duration of Catheter was greater than 4 weeks with a mean duration of 3.17 weeks. The mean hemoglobin was $11.30 \mathrm{~g} / \mathrm{dl}$. The commonest presenting complication was urinary retention at $25.8 \%$ (8/31) followed by hematuria $16.1 \%(5 / 31)$. Hypertension $41.9 \%(13 / 31)$ and diabetes $6.5 \%(/ 31)$ were the commonest comorbidity. The rate of postoperative complication was $38.7 \%$ with the commonest being surgical site infection $16.1 \%(5 / 31)$ and clot retentions $9.7 \%$ (3/31). There was a high rate of transfusion was $77.4 \%$ (24/31) patients. Up to about $13 \%(4 / 32)$ patients had coexisting stricture with $6.5 \%(2 / 31)$ patients treated with urethroplasty and 6.5\% (2/31) patients treated by dilatation. The mortality rate was $6.5 \%(2 / 31)$ from renal impairment and severe sepsis. Conclusion: BPH is a common cause of lower obstructive uropathy. Most patients present with complications of the disease such as refractory symptoms, bladder stones or diverticulae necessitating surgery. However, due to the absence of endourological equipments in most parts of Africa and the large prostate at presentation, most settings consider open transvesical prostatectomy as a viable option. The perioperative mor-
\end{abstract}


bidity is relatively higher, but the outcome remains acceptable.

\section{Keywords}

Benign Prostatic Hyperpalsia (BPH), Perioperative Complication, Lower Obstructive Uropathy, Open Transvesical Prostatectomy

\section{Introduction}

Benign Prostatic Hyperplasia (BPH) is one of the commonest causes of lower obstructive uropathy and usually presents with lower urinary tract symptoms [1] [3]. Most patients in the developed nations seek earlier care and are usual candidates for the less invasive transurethral resection of the prostate (TURP) [1]. However, in developing nations, the presentation is late often large prostate and associated complications of bladder outlet obstruction (diverticulae, stones, impaired renal function etc.) warranting open prostatectomy [1].

Prostatectomy is one of the most commonly performed operations across the world [2]. Open prostatectomy has been the only surgical option for the management of BPH during most of the 20th century, however the frequency of open prostatectomy has gradually decreased with the widespread use of endoscocpic equipments [2]. Transurethral resection of the prostate (TURP) is now considered as the gold standard for treatment of BPH because it is less invasive methods, cost effectiveness with lower morbidity [2] [3].

Though the usual indications of open transvesical prostatectomy includes an adenoma of $80 \mathrm{cc}$ or greater with associated bladder stone or diverticulum; yet another important indication is the absence of endourological equipments common in most African settings [2]. Open prostatectomy offers the advantages of a lower re-treatment rate and more complete removal of the prostate adenoma under direct vision, while it avoids the risk of additional hyponatremia (TURP syndrome) [4].

Therefore, the objective of this study is to share our experience of perioperative outcomes of open transvesical prostatectomy over a year involving two referral centers in Monrovia Liberia and establish baseline information about the procedure and outcome; to our knowledge no such information has been earlier documented in Liberia.

\section{Materials and Methods}

The study was performed at two hospitals, The John F. Kennedy medical Center and the Saint Joseph Catholic Hospital in Monrovia. A total of 31 patients were included in the study. The hospitals' records were retrospectively reviewed from February 2018 to February 2019 for cases of open transvesical prostatectomy and data on age, presentation, duration of catherization, perioperative complications, transfusion requirement and associated urethral stricture were retrieved and recorded. 
Patients with retropubic prostatectomy were excluded from the study. All patients in the study had a preoperative ultrasound assessing prostate volume, residual bladder volume, bladder stones and evidence of hydronephrosis. The indication for open transvesical prostatectomy was independent of prostate volume as there was no other option as transurethral resection or Holium Laser enucleation of the prostate in both facilities.

Indications of prostatectomy included patient with $\mathrm{BPH}$ refractory to medical treatment or presenting with complications as recurrent acute urinaryretention, chronic urinary retention, bladder stones, recurrent urinary tract infection, hernia, hemorrhoids, obstructive uropathy and recurrent hematuria. The standard open transvesical prostatectomy was performed under regional or general anesthesia with the patient in the supine position. A pfannistiel incision was used and the bladder mobilized of the surrounding perivesical fat. A longitudinal incision was made to explore the intravesical cavity and the patency of the ureteral meatus assessed. An appropriate plane between the adenoma and the prostate capsule was developed. The adenoma was dissected off using the index finger until the attachment of the distal urethral which was cut off using a Metzenbaum scissors. Harris' Stitch and balloon tamponade were used to achieve hemostasis in the prostatic fossa. A 3-way $22 \mathrm{Fr}$ catheter was left in place for irrigation with normal saline. The irrigation was stopped after the irrigation fluid appeared clear usually on the $2^{\text {nd }}$ or $3^{\text {rd }}$ day postoperatively.

Postoperatively, all patients had a complete blood count but patients with postop hemoglobin of $8 \mathrm{~g} / \mathrm{dl}$ or lower were transfused. Normal Creatinine, blood urea and nitrogen as well as serum electrolytes were also surrogate of early discharge. The patients received postoperative antibiotics for a minimum of 72 hours. Follow ups were done weekly for 4 weeks in the urologic clinic and then subsequently as required. Catheters were removed around postoperative day 14 unless dictated by post-operative complications.

The data was analyzed using IBM SPSS data editor and the results are presented as percentage or mean standard deviation

\section{Result}

This was a multicenter retrospective study from February 2018 to February 2019 involving a total of 31 patients treated for benign prostate hyperplasia. The study showed in (Table 1$)$ a mean age of 64.6 years $(S D=9.03)$ with a range $52-85$ years. The commonest age range managed for $\mathrm{BPH}$ in our study as shown in (Table 2) was 61 - 70 years comprising $41.9 \%$ (13/31) followed by age range 51 60 years about $35.5 \%$. The study showed that $54.8 \%$ (17/31) of patients had preoperative catheter placed either for urinary retention or hematuria. The maximum duration of Catheter was greater than 4 weeks with a mean duration of 3.17 week. Hemoglobin was as low as $6.90 \mathrm{~g} / \mathrm{dl}$ with the mean hemoglobin at $11.30 \mathrm{~g} / \mathrm{dl}$. In (Table 3 ), most of the patient presented with urinary retention at $25.8 \%(8 / 31)$ followed by hematuria $16.1 \%(5 / 31)$ which were treated as emergency. Other complications on presentation include hernia $9.7 \%(3 / 31)$, 
Table 1. Clinical parameters.

\begin{tabular}{cccccc}
\hline & $\mathrm{N}$ & Minimum & Maximum & Mean & Std. Deviation \\
\hline Age & 31 & 52.00 & 85.00 & 64.6452 & 9.03898 \\
$\begin{array}{c}\text { Duration of Preop } \\
\text { Catheter (wks) }\end{array}$ & 17 & 1.00 & 4.00 & 3.1765 & 1.18508 \\
Hemoglobin & 31 & 6.90 & 16.00 & 11.3097 & 2.05237 \\
\hline
\end{tabular}

Table 2. Age range of patients presenting with BPH.

\begin{tabular}{ccc}
\hline Age in Years & Frequency & Percent \\
\hline $51-60$ & 11 & 35.5 \\
$61-70$ & 13 & 41.9 \\
$71-80$ & 6 & 19.4 \\
$81-90$ & 1 & 3.2 \\
Total & 31 & 100.0 \\
\hline
\end{tabular}

Table 3. Complications at presentation of patients with BPH.

\begin{tabular}{ccc}
\hline & Frequency & Percent \\
\hline Urinary Retention & 8 & 25.8 \\
Haematuria & 5 & 16.1 \\
Hernia & 3 & 9.7 \\
epidydimo-orchitis & 3 & 9.7 \\
Stones & 1 & 3.2 \\
Urinary Retention and Stones & 1 & 3.2 \\
Urinary Retention and hernia & 3 & 9.7 \\
None & 7 & 22.6 \\
Total & 31 & 100.0 \\
\hline
\end{tabular}

epidydimo-orchitis $9.7 \%$ (3/31), urinary retention and hernia 9.7\% (3/31), urinary retention and stones 3.2\% (1/31). Hypertension $41.9 \%(13 / 31)$ and diabetes $6.5 \%(2 / 31)$ were the commonest comorbidity. These patients were managed along with an Internist for optimization before surgery.

The total postoperative complications in (Table 4) was about $38.7 \%$ with surgical site infection accounting for $16.1 \%$ (5/31) which was treated with continuous wound care. There were 3 clot retentions 9.7\%; two were taken back for relook cystostomy and clot expulsion. Another was treated by forceful irrigation. One patient developed vesicocutaneous fistula that closed spontaneously after 21 days of catherization while another developed pelvic abscess that was drained surgically. The rate of transfusion in the series was $77.4 \%(24 / 31)$ patients. Up to $13 \%(4 / 32)$ patients had coexisting stricture with $6.5 \%(2 / 31)$ patients treated with urethroplasty and $6.5 \%(2 / 31)$ patients treated by dilatation prior to prostatectomy. The mortality rate was $6.5 \%(2 / 31)$ from renal impairment and severe 
Table 4. Postoperative complications of transvesical prostatectomy.

\begin{tabular}{ccc}
\hline & Frequency & Percent \\
\hline None & 19 & 61.3 \\
pelvic abscess & 1 & 3.2 \\
orchitis & 2 & 6.5 \\
clot retention & 3 & 9.7 \\
surgical site infection & 5 & 16.1 \\
vesico-cutaneous & 1 & 3.2 \\
Total & 31 & 100.0 \\
\hline
\end{tabular}

sepsis following a fulminant necrotizing infection in one diabetic patient. However, the 3-month postoperative follow-ups of the rest of the patients were unremarkable.

\section{Discussion}

Currently, there are various modalities for the surgical management of BPH but TURP is the now the gold standard because of its cost effectiveness, less invasiveness with fewer complications [2] [3] [5]. Holium laser enucleation of the prostate is even being considered as an alternative to open prostatectomy for large prostate not amenable to TURP due to its good outcome and safety profile [1] [5]. However, the initial setup and maintenance of these endourological equipments are far from being available in most sub-Saharan and developing nations [2]. Therefore, open prostatectomy is still to date a suitable option for $\mathrm{BPH}$ refractory to medical treatment and those presenting with complications [1] [3] [5]. Open transvesical prostatectomy may offer some benefits because it allows inspection of the bladder in the absence of cystoscopy and simultaneously treat complications as bladder stone and diverticula [4] [5].

Data from our study displayed a mean age of $64.6 \pm 9.03$ years with a range 52 - 85 years. This finding is consistent with six retrospective studies in other developing nations Liaqat Ali et al. (2008), Khattak S. et al. (2004), Ugwumba et al. (2014), Berhanu et al., Ibrahim et al. (2013), Salako et al. (2016), which found similar results (67.8 years, 63.4 years, $65.2 \pm 6.8$ years, $63.8 \pm 9.9$ years, $63.8 \pm$ 9.9, 67 years) respectively [2] [3] [6] [7] [8]. Nevertheless, a few retrospective studies [1] [10] showed a higher mean age in the $7^{\text {th }}$ decade of life. The age specific prevalence in our series was commonest amongst patients $61-70$ years comprising 41\% (13/31). This result concurred with Berhanu et al., and Khattak S. et al. who reported their highest prevalence in the $6^{\text {th }}$ decade.

This study demonstrated a high level of preoperative catheterization at $54.8 \%$ with a mean duration of 3.14 weeks. The prolonged preop catheterization was attributed to most patients presenting with urinary retention with associated alteration in electrolytes and renal function that needed correction before surgery. 
Results from many retrospective studies in sub-Saharan African showed varying duration of preoperative catherization ranging from 1 week to 58 weeks [3] [6] [7] [9]. The heterogeneity in the data could be based on the availability of Urologist, the presentation of patients, the local expertise and local guidelines of management.

Most of the patients presented with urinary retention at $25.8 \%$ followed by hematuria $16.1 \%$ and were treated as emergency. Liberia is a developing nation with most patients not affording basic healthcare. This accounts for the late presentations with associated high numbers of presenting complications. Most contemporary series from Ghana, Nigeria and East Africa [1] [2] [4] [6] [9] [11] have shown that urinary retention is the commonest presenting complication with refractory urinary retention being a common indication for surgery.

The total early postoperative complications in our study was about $38.7 \%$ with surgical site infection accounting for $16.1 \%$ followed by clot retention. There is an obvious variation amongst many studies Liaqat Ali et al. (2008), Ugwumba et al. (2014), Berhanu et al. Ibrahim et al (2013), Salako et al. (2016), Moslemi et al. (2010), Ceylan et al. (2006), Kyei et al. (2012), the commonest postoperative complications to each were ( febrile urinary tract infection, urinary tract infection, clot retention + wound infection, transient incontinence, surgical site infection, epididymo-orchitis, clot retention + epididymo-orchitis, clot retention) respectively. Despite the heterogeneity in the various study populations, it is obvious that infectious complications and clot retention are consistent findings. This indicates that measures for infection control and correction of coagulopathy are crucial for open prostatectomy. The practice of urology in Liberia is evolving and so its nursing care. There were lapses in continuous bladder irrigation, contributing to clot retention with leaked irrigation fluid to the pelvis possibly leading to wound infection and pelvis abscess.

There was a relatively high transfusion rate in our series $77.4 \%(24 / 31)$ patients. The fact that patients presented with a hemoglobin as low as $6.90 \mathrm{~g} / \mathrm{dl}$ with the mean hemoglobin at $11.30 \mathrm{~g} / \mathrm{dl}$ could have contributed to the high perioperative transfusion rate. All the procedures were done by a surgical resident and a Urologist Consultant for teaching purpose. This could have accounted for some of the blood loss requiring transfusion. One study in Nigeria, Ibrahim et al. (2013), showed a similar high transfusion rate of $68.98 \%$ in total as the inclusion criteria was prostate weighing more than 200 grams. However other literature reviewed a much lower transfusion rate ranging from $5 \%$ to $30 \%$ [2] [4] [5] [6] [7] [10]. The mortality rate was 6.5\% (2/31) from renal impairment and severe sepsis following a fulminant necrotizing infection in one diabetic patient. Most studies [1] [2] [4] [5] [7] [10] reported no mortality during their series, However, other literature [3] [6] [8] [9] [12] [13] showed a mortality rate around $1 \%$. Most of these deaths were attributed to pulmonary embolism and severe postoperative hemorrhage. The marked difference in our data could be possibly explained by the relatively lower sample size giving a higher mortality rate. 


\section{Study Limitation}

This study is challenged by its retrospective design which is subject to selection bias. The relatively lower sample size limits the potential for a more robust statistical and comparative analysis with other high-volume studies.

\section{Conclusion}

$\mathrm{BPH}$ is a common cause of lower obstructive uropathy. Most patients present with complications of the disease such as refractory symptoms, bladder stones or diverticulae necessitating surgery. However, due to the absence of endourological equipments in most parts of Africa and the large prostate at presentation most settings consider open transvesical prostatectomy as a viable option. The perioperative morbidity is relatively higher, but the outcome remains acceptable.

\section{Conflicts of Interest}

The authors declare no conflict of interest towards this publication.

\section{References}

[1] Ibrahim, A.G., Aliyu, S. and Ali, N. (2013) Open Prostatectomy for Huge Prostates: Our Experience in a Developing Country. Tropical Medicine and Surgery, 1, 132.

[2] Ali, L., et al. (2008) Transvesical Prostatectomy in Elderly Patients: An Experience at Saidu Teaching Hospital Swat. Annals of Pakistan Institute of Medical Sciences, 4, 148-151.

[3] Khattak, S., Kamal, A. and Khattak, A.M. (2004) Surgical Treatment of Benign Prostatic Hyperplasia. 123-126.

[4] Moslemi, M.K. and Zadeh, M.A. (2010) Simple Suprapubic Prostatectomy. Urology Journal, 7, 51-55.

[5] Elshal, A.M., El-Nahas, A.R., Barakat, T.S., Elsaadany, M.M. and El-Hefnawy, A.S. (2013) Perioperative Outcome of Transvesical Open Prostatectomy. Arab Journal of Urology, 11, 362-368. https://doi.org/10.1016/j.aju.2013.06.003

[6] Ugwumba, F.O., Ozoemena, O.F., Okoh, A.D., Echetabu, K.N. and Mbadiwe, O.M. (2014) Transvesical Prostatectomy in the Management of Benign Prostatic Hyperplasia in a Developing Country. Nigerian Journal of Clinical Practice, 17, 797-801. https://doi.org/10.4103/1119-3077.144402

[7] Berhanu, N.A. (2013) The Safety and Efficacy of Trans-Vesical Prostatectomy Done at a Primary General Hospital Setting in Ethiopia. East and Central. African Journal of Surgery, 13, 53-60.

[8] Ibrahim, A.G., Nuhu, A. and Aliyu, S. (2012) Ten-Year Experience with Open Prostatectomy in Maiduguri. ISRN Urology, 4, 4068-4072. https://doi.org/10.5402/2012/406872

[9] Salako, A.A., Badmus, T.A., Owojuyigbe, A.M., David, R.A., Ndegbu, C.U. and Onyeze, C.I. (2016) Open Prostatectomy in the Management of Benign Prostate Hyperplasia in a Developing Economy. Open Journal of Urology, 6, 179-189. https://doi.org/10.4236/oju.2016.612029

[10] Ceylan, K. (2006) Open Prostatectomy-The Results of a Series of 320 Cases in Rural Area. European Journal of General Medicine, 3, 11-15. https://doi.org/10.29333/ejgm/82354 
[11] Kyei, M.Y., Mensah, J.E., Morton, B., Gepi-Attee, S., Klufio, G.O. and Yeboah, E.D. (2012) Surgical Management of BPH in Ghana: A Need to Improve Access to Transurethral Resection of the Prostate. East African Medical Journal, 89, 241-245.

[12] Ngugi. P.M. and Saula, P.W. (2007) Open Simple Prostatectomy and Blood Transfusion in Nairobi. East African Medical Journal, 84, 12-23.

https://doi.org/10.4314/eamj.v84i9.9557

[13] Condie Jr., J.D., Cutherell, L. and Mian, A. (1999) Suprapubic Prostatectomy for Benign Prostatic Hyperplasia in Rural Asia: 200 Consecutive Cases. Urology, 54, 1012-1016. https://doi.org/10.1016/S0090-4295(99)00307-6 